\title{
Representations of Inclusion: How Pre-service Teachers Understand and Apply Inclusion Across Situations
}

\author{
Christopher P. Ostrowdun \\ University of Calgary
}

\begin{abstract}
As education marches toward inclusive practices, it is clear not everyone perceives inclusion in the same ways. This article unpacks pre-service teachers' perspectives toward inclusion. Using a design-based approach, enrolled in a Canadian bachelor of education program created drawings about inclusion. Through the lens of figured worlds and visual analysis, these drawings were compared to pre-service teachers' other course work and practicum placements to better understand their perspectives on inclusion in different contexts. The findings show differences between the ideals pre-service teachers conveyed through drawings and their approaches to pragmatic tasks, such as creating an individualized education or inclusive lesson plan. Furthermore, there was a considerable range of sophistication in pre-service teachers' ideas of inclusion, with some pre-service teachers focusing on accessible materials while other pre-service teachers addressed more holistic notions of inclusive environments and systems. Making connections between pre-service teachers' perspectives and their teacher training is critical for pre-service teachers to develop robust understandings of inclusion and a greater awareness of how their perspectives shape teaching practices.
\end{abstract}

Teachers' experiences of and perspectives on the world shape what they prioritize, care about, and do in their classrooms (Jordan \& Stanovich, 2003; Kim, 2011; Silverman, 2007). Broadly, inclusive education acknowledges and embraces human differences, and creates equitable learning opportunities for all students (Lawrence-Brown \& SaponShevin, 2014). In Canada and the United States, 13\% of youth are considered disabled 
(National Centre for Education Statistics, 2019; Morris et al., 2018); this figure climbs to $25 \%$ when also considering students who require significant learning supports (Alberta Teachers' Association, 2015). Disability impacts every student, teacher, and classroom, so it is vital to support pre-service teachers in developing robust understandings of inclusion.

Pre-service teachers typically support inclusion, but variation in how they understand inclusion also influences their practices (Burke \& Sutherland, 2004; Markova et al., 2016; Savolainen et al., 2012). Previous research has explored teachers' overall beliefs, attitudes, and sentiments toward inclusion, but limited literature exists on how pre-service teachers understand inclusion and apply their ideas of inclusion in different situations, at a finegrained level (Jordan \& Stanovich, 2003; Loreman \& Earle, 2007; Sokal \& Sharma, 2017). In what ways do pre-service teachers understand inclusion? How do pre-service teachers integrate their perspectives of inclusion in different situations, such as in course tasks and during practicum placements? How do pre-service teachers' perspectives evolve over time? This article reports my investigation into these questions. Through the lens of figured worlds, I examine drawings about inclusion produced by pre-service teachers (Holland et al., 1998). Coupled with data from pre-service teachers' coursework and interviews, I investigate how pre-service teachers convey and describe inclusion in different assignments, tasks, and practicum placements during their teacher training.

\section{Theoretical Framework}

\section{Figured Worlds}

Think about a classroom. You might imagine a teacher, students, desks, and chairs. In this environment, there might be learning activities, assignments, and tests. Social conventions presume the teacher commands authority and students follow expected classroom behaviours. This type of common understanding of a classroom makes up a figured world, which are "socially and culturally constructed realm[s] of interpretation in which particular characters and actors are recognized, significance is assigned to certain acts, and particular outcomes are valued over others" (Holland et al., 1998, p. 52). A figured world is a frame of interpretation comprised of taken-for-granted assumptions and storylines about environments, activities, participants, and interactions (Gee, 2011). Figured worlds shape how people interpret and engage with daily life (Holland et al., 1998). The components of figured worlds are both localized and generic enough to be recognizable in different contexts (Holland et al., 1998). For example, if someone walks into a grocery store anywhere in the world, they can assume a general practice of exchanging goods for money even if they do not speak the local language or need to use a different currency. Figured worlds are useful for understanding how people orient themselves in a given context, but figured worlds are also not static. For instance, students with disabilities were historically segregated into special schools, but over time society has shifted toward the holistic inclusion of all students in mainstream schools (DePoy \& Gilson, 2011).

A figured world characterizes particular people, actions, and values. In Thorius's (2016) study, special education teachers took on clear roles as remediators and diagnosticians of student pathologies. Within that world, identifying a student's challenges was valued as a key practice, which guided not only support strategies, but 
also how the special educators discussed or referred to the student, for example, "He's pretty LD [learning disabled]" (Thorius, 2016, p. 1334). A world is also made up of taken-for-granted practices that newcomers to that world often perpetuate because the world has sanctioned such practices as appropriate and valued. For example, support plans for students with diagnosed needs often include goals to track a student's progress, and frequently such goals are put in quantifiable terms (e.g., spelling accuracy) because of historical norms that valued quantitative metrics and not because they best reflected or supported a student's learning (Thorius, 2016).

Figured worlds also mediate how newcomers to a world position themselves, organize their thoughts, and behave. Bennett et al. (2017) examined how medical students perceived what a "good doctor" should be and do. The students judged themselves, and other practising doctors, against the world of medicine. The world set expectations such as how doctors should or should not interact with patients and how to balance professionalism with empathy. In reflecting on their clinical placements, the students critiqued their performances and rationalized good versus bad behaviours to highlight areas for future improvement. Like teachers, how the medical students constructed worlds had real consequences for how they participated in their professional practice. Figured worlds offer a way to frame people's perspectives and understand their orientations to participation in daily life.

\section{Visual Representations}

Visual representations (drawings, in this case) function as artifacts of how people conceive a topic. Artifacts help "open up" (Holland et al., 1998, p. 61) figured worlds, and exploring other artifacts allow people to encounter different worlds. Artifacts "are the means by which figured worlds are evoked, collectively developed, individually learned, and made socially and personally powerful" (Holland et al., 1998, p. 61). The artifacts represented within a drawing also hold meaning about the "worlds to which they were relevant, and position individuals with respect to those worlds" (Holland et al., 1998, p. 63). Visual representations show the figured worlds people exist in, shape, and encounter.

Drawing externalizes storylines using colours, scales, symbols, and objects into a visual form (Albers et al., 2009). Drawings can convey what a person finds salient, and which people and actions they value - a glimpse into a figured world. Albers et al. (2009) studied how children construct understandings of gender through drawing about the interests and experiences of a person of another gender. The drawings revealed subtle yet meaningful differences in children's perspectives. Girls used more colour, details, and curved lines in their drawings about boys. These signaled gender stereotypes of girls favouring bright colours and, as the authors noted, social dynamics such as greater acceptance for girls to engage in boys' interests than the other way around (e.g., a girl's detailed depiction of a boy playing football versus a boy's simple depiction of a girl dancing; Albers et al., 2009). Such findings give insight into the assumptions, social interactions, and behaviours people associate with other worlds. Drawings also show how people relate to different worlds. Visual representations offer a pedagogical tool enabling 
students to weave their perspectives into what they are taught, as well as a research tool for examining how students construct understanding about a topic.

Phillipson and Forlin (2011) bridged inclusion, drawings, and teacher education in a study of new teachers in Hong Kong who read articles about diversity and then visually represented an "issue of contention or interest regarding inclusive education in Hong Kong" (p. 5). The drawings reflected not only the participants' perspectives but also broader sentiments: The depictions of a dragon boat race or a hurdles race implicitly referenced the hyper-competitive nature of schooling in Hong Kong, where part of inclusion meant enabling students to compete. There were also contrasts between the drawings, with some showing a positive perspective of teachers nurturing students while other drawings emphasized challenges faced by teachers such as pressure from many demands with little respite or unstable support structures. The researchers argued that visual imagery encouraged teachers to think critically about their beliefs and values, and that it allowed teachers to connect their experiences to the concept of inclusion within their socio-cultural contexts.

\section{Methods}

As part of a team of instructors and researchers, I used design-based research (McKenney \& Reeves, 2012) to implement a drawing assignment within a 9-week, firstyear bachelor of education course at a Canadian university. The drawing and reflection assignments were created as part of this research and integrated among existing course activities. In the first week, each PST created an individual drawing (along with a 100word description of what they drew) in response to a prompt: "What do you think inclusion is as a concept?" The pre-service teachers were supplied with markers and letter-size paper, and they had approximately 20 minutes to complete their drawings and descriptions. Intentionally, this was done in the first week of the course and with minimal instructions, to capture the pre-service teachers' instinctive responses before they were potentially coloured by the course content. I scanned and uploaded the drawings to an online gallery that was available to all pre-service teachers in the course. My colleagues and I used the repository of drawings to inform class discussions about trends in preservice teachers' perspectives and how these perspectives were situated within course content. The pre-service teachers did not modify or revise their drawings but did have an opportunity to review them using the online gallery.

Two other course assignments included creating an individualized education plan (IEP) and a lesson plan that aligned with the principles of Universal Design for Learning (UDL; Meyer et al., 2014), which were completed in the fourth and eighth weeks, respectively. The designs of these two assignments predated this research and were unchanged. The pre-service teachers worked in small groups to create an IEP based on an authentic psycho-educational assessment report of a student. The IEP had to outline a student's needs, accommodations, goals, and strategies to support their needs. The preservice teachers also wrote a summary (500 words) of the IEP addressed to the student's parents. In the UDL assignment, the pre-service teachers worked in groups to explain (in 250 words) how their lesson plan aligned with UDL and with the needs of a given class profile. Each profile included a mix of 24-31 students with and without specific 
characteristics of disabilities or support requirements. In the course's final week, the preservice teachers wrote a reflection (200 words) about their drawings, about how their ideas had evolved, and about what might change if they were to repeat the drawing task. All 371 pre-service teachers enrolled in the course did the activities as outlined above regardless of their participation in the study. As well, for all group tasks for participants and non-participants, students self-selected their groups. After the course, the pre-service teachers also did 4-week practicum placements in local schools, where they prepared and led learning activities.

Since I was one of the course instructors, the recruitment and consent procedures were carried out by a third party and I was not informed which pre-service teachers agreed to participate until after the course was complete. In total, 92 pre-service teachers consented to participate in one or more parts of the research. Since the study was integrated as part of regular class activities, participants and non-participants sometimes unknowingly ended up working together on group tasks. Only coursework where all group members consented was used as data. Here, I highlight the 11 pre-service teachers with complete data sets for individual drawings, IEP and UDL assignments, and reflections to establish arcs across multiple points in the course. Two of the 11 participants each agreed to an interview, which was audio-recorded and transcribed, postpracticum to complement the other data sources. In the interviews, I asked the participants to describe their drawings, what inspired their drawings, and if there was anything they had wished to draw but were unable to. I also asked each participant to recount their attempts to implement inclusion during practicum and how their perspectives on inclusion might have evolved after teaching in real-world classrooms.

\section{Analysis}

I analyzed the data across two axes: first, the overall themes of the pre-service teachers' ideas, language, and metaphors of inclusion as expressed through their drawings and corresponding descriptions; and second, the arcs of how their ideas, language, and metaphors of inclusion manifested across the drawings, assignments, reflections, and interviews. I first conducted a visual discourse analysis of the participants' drawings to consider the visual composition, how and which people, places, and activities were depicted, what was prominent, symbols and their meanings, and relationships between people and objects (Albers, 2007; Albers et al., 2009; Gee, 2011). Simultaneously, I referenced and coded the corresponding drawing descriptions to substantiate my interpretations using the participants' own words. This coding based on the drawings and descriptions informed the overall themes of the participants' perspectives.

Next, I compared the drawings and descriptions with the remaining data: IEP parent summaries, UDL assignments, reflections, and interview transcripts. Given this data was text-based, I looked for written expressions of how and what people and activities were described, what was prominent, locations, metaphors (e.g., teaching, learning, disability, accommodations), and relationships between people and objects, to parallel my analysis of the drawings. Since I had substantiated the drawing analysis using the participants' written descriptions, it was possible to compare these with the remaining text-based data sources. My colleagues and I reviewed the data for consistency in coding and 
interpretations to leverage the strength of having multiple data sources while also mitigating the added complexity of such an approach. As a caveat, since pre-service teachers were not explicitly asked to discuss their personal perspectives in the IEP and UDL assignments, the analysis focused on the phrasing and wording pre-service teachers used in describing and supporting students' needs. When comparing the data, I looked for similar wording and tone, which I used to identify pre-service teachers' integration of their perspectives across the drawing task, assignments, and practicum placements.

\section{Findings}

I organize the findings into two sections that review how participants conveyed the figured world of inclusion: (a) as a utopian world of ideals, and (b) as a pragmatic world of enacting inclusion. These worlds were related and overlapping, but a comparison of their drawings to their assignments and to their practicum experiences shows that participants invoked a range of priorities. The first section outlines the overall themes of the utopian version of an inclusive world based on the 11 individual participant drawings and descriptions. The second section compares the participants' drawings and descriptions against the other data sources to track how the participants conveyed inclusion over time. Note, participants' names have been replaced with pseudonyms.

\section{Utopia}

I use the term utopia to reflect an idealistic or desirable world, typically represented through metaphors or high-level ideas. Such ideals show what the participants found salient in their perspectives. Four prominent themes arose from the drawings and descriptions (the drawings themselves are shared in the Pragmatics section): pathways, interpersonal connections and relationships, expressions of diversity, and expressions of emotion.

\section{Pathways}

Pathways position learning and inclusion as a conduit between a current state and a desired state. I considered pathways to be expressions of movement (e.g., arrows), such as different pathways of learning (Figure 3a); various backgrounds, interests, and topics moving into a space (Figure $3 \mathrm{~b}$ ); or the exchange of information between people (Figure 1b).

\section{Connections and Relationships}

Several drawings depicted connections and relationships between people, such as students holding hands (Figure 1c, 4a). These drawings relay a sense of community, whereby being together is considered beneficial. Some participants took a more metaphorical stance, such as representing people around a globe (Figure 5a), while others targeted specific strategies for collaboration and valuing different contributions. 


\section{Expressions of Diversity}

The participants all depicted or described diversity explicitly, such as in terms of cognition (skills, abilities, knowledge), background (ethnicities, cultures, languages), physical appearance (size, shape, hair, apparel, mobility), gender identity, and sexual orientation. Depicting as much diversity as possible was common to 8 of 11 drawings, in which most people or objects rendered were unique. Curiously, most drawings excluded students from dominant groups (e.g., non-disabled, typically achieving) and did not reference similarities among students. Seven drawings (e.g., Figure 4a) represented diversity using common markers of difference such as appearance, physical abilities, or cognitive attributes. The other four drawings (e.g., Figure 2b) used more abstract representations of diversity including symbols, geometric shapes as torsos, or altered body parts.

\section{Expressions of Emotion}

Common to most drawings were people expressing positive emotions, such as smiles or happiness (e.g., Figure 5b). Other affective attributes found in the drawings and descriptions, including love, compassion, empathy, and harmony, portray inclusion as encompassing more than academic performance, a collection of accommodations, or sharing a geographic space. The near-ubiquitous reference to positive emotions across the drawings reinforces an impression of inclusion as a utopian world.

\section{Pragmatics}

To see how the participants' ideas of inclusion manifested over time and across the data points, I compared the participants' drawings and descriptions with the IEP and UDL assignments, reflections, and post-practicum interviews. I looked for consistencies and disconnects between the ideas conveyed in the participants' drawings and the other data points. The data is organized according to the participants' working groups for the IEP and UDL assignments. The findings for each working group are subdivided by data sources (i.e., drawings, IEP and UDL assignments, reflections, and interviews) and compared. The five groups were: Group A: Cheryl, Alice, and Susan; Group B: Kelly and Marcy; Group C: Beth and Emily; Group D: Judy and Tanis; and Group E: Melanie and Julia.

\section{Group A: Cheryl, Alice, and Susan}

Cheryl addressed the broadest range of diversity, mentioning academic ability, physical difference, gender, socio-economic background, giftedness, and ethnicity in her drawing description (Figure 1a). She also linked these identifiers to symbols: a wheelchair for physical disability, a light bulb for giftedness, a question mark for "needs extra support," and "jumping jacks because he requires physical movement ... to focus" (drawing description). Cheryl summarized inclusion as "students of all backgrounds and abilities will be welcome in my classroom, and I will do my best to support each student['s] ... learning needs" (drawing description). Her phrasing of "my classroom" and "I will ... support" positions her as the central enabler of inclusion and relegates students to passive participants rather than contributors to an inclusive environment. Cheryl drew and described diverse students in a common space but stopped short of describing how this translated to inclusive learning. 
Figure 1. Group A Drawings of inclusion.

a. Cheryl

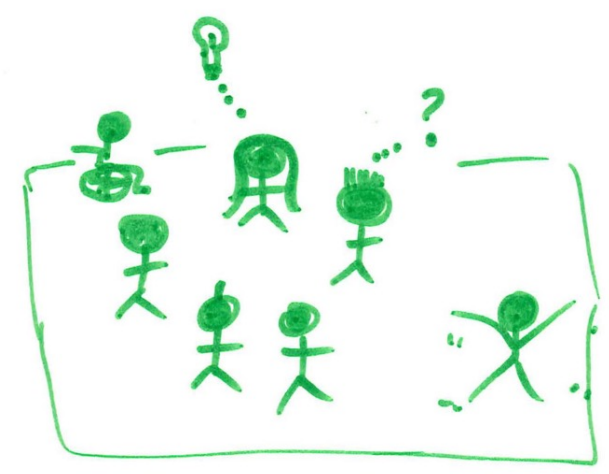

b. Alice

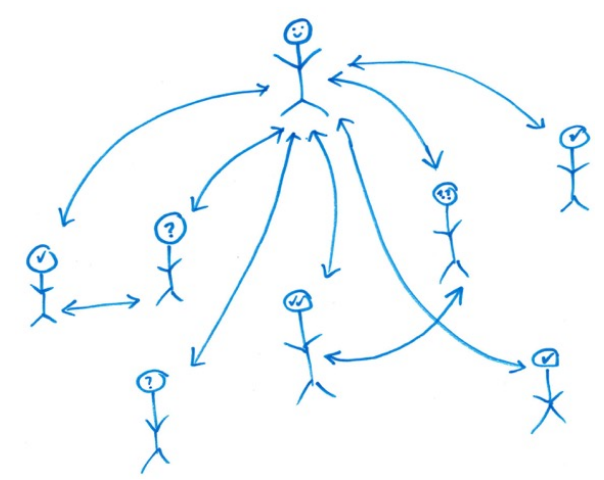

\section{c. Susan}

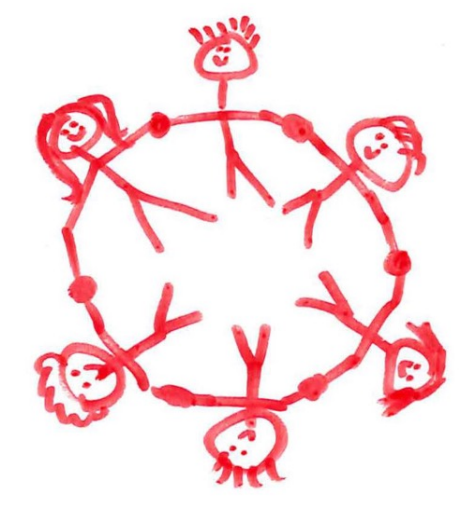

Alice (Figure 1b) emphasized diverse "abilities and levels of understanding and competency," stating that "the arrows signify the exchange of information between teacher and student ... via various forms of assessment" (drawing description). All students have arrows going to and from the teacher, but only two pairs of students have arrows going between them-aligning with a teacher-centred approach to learning whereby knowledge and competencies are the currency in establishing rank (Robinson, 2007). As well, having the teacher at the top of the drawing follows conventions of composition according to which elements at the top of a drawing are attributed more significance than those at the bottom (Kress \& van Leeuwen, 2006). At the same time, Alice mentioned interactions between students with "different levels of competency working together to help each other" (drawing description). While there is a hierarchy, learning is bi-directional between students and the teacher: "both may learn from each other" (drawing description). Check-marks and question-marks in lieu of faces for students reinforce a metaphor of students as containers of knowledge. In this world, academic performance was prized and was the primary metric of diversity.

In contrast, Susan (Figure 1c) drew people standing in a circle, "holding hands to show a sense of community" (drawing description). She said, "Inclusion should feel 
warm and welcoming. Everyone should feel a part of a 'safe space' where differing opinions and views are heard and valued" (drawing description), implying ownership and an affective connection between people and space. The absence of a teacher in Susan's drawing, combined with her description of valuing differing views, signals a world in which inclusion is enabled by the collective rather than a central authority.

Cheryl and Alice: IEP. According to Cheryl and Alice, their IEP student had "many strengths, including being a kind, empathetic girl with a good sense of humour ... [who] makes a valuable contribution to our school by helping [other students]" (IEP parent summary). Cheryl's and Alice's attention to the student's personality traits notably goes beyond the assignment requirements. In their drawing descriptions, Cheryl and Alice described student attributes such as gender, socio-economic backgrounds, disabilities, and academic abilities; however, affective aspects like empathy or kindness were absent, indicating a divergence in priorities between their drawings and the IEP task.

Cheryl, Alice, and Susan: UDL. The group's discussion of UDL echoed elements of Cheryl's drawing description, which focused on addressing each student's needs, as well as Alice's, which focused on inclusion as a mechanism for supporting performance. They group presented UDL as a matched list of student needs and supports. Some examples included, "[the] fast pace of the lesson would be helpful keeping Hayden, Neeva, and Julia on task," "[the teacher] checks in periodically with Oliver to ensure his anxiety is under control," and "Cody [could] ... express his ideas in formats other than writing. Julia would benefit from the opportunity to show her work" (UDL assignment). These examples frame UDL as a mechanism for supporting academic performance and behaviour management, which maps to some of the group members' ideas expressed in their drawings and descriptions but misses others. This world lacks, for instance, Cheryl's and Susan's ideas of community or collaborative learning.

Cheryl, Alice, and Susan: Reflection. Cheryl's drawing and description did not reference emotion; however, this changed in her reflection. She described how her daughter's recent experiences of a psycho-educational assessment made her realize how "abilities in emotional regulation have a big [e]ffect on classroom learning and instruction" (reflection). Cheryl's revised world speaks to the malleability of figured worlds and how personal histories in one world (e.g., home life) reshape interpretation and participation in other worlds (Holland et al., 1998).

Alice's ideas "stayed mostly the same" (reflection) but she noted UDL as a new approach to "benefit everybody in the classroom, not just certain individuals" (reflection). She expressed concern about being able to "differentiate" for students, "assess my student's individual understanding on a regular basis," and "maintain classroom control if a student needs one-on-one attention" (reflection). A paradoxical tension exists between her teacher-centred emphasis on control and performance, and her support for UDL, which espouses a decentralized and life-long learning approach. Alice reinforced her initial focus on performance with added strategies inspired by UDL.

Susan's perspectives also evolved. Initially, she wrote "inclusion should feel warm and welcoming" (drawing description). By the end of the course, she realized there was considerable depth and complexity in how "teaching practices shape the classroom 
environment" (reflection) and enable inclusion. Cheryl's and Susan's reflections show a broadened understanding of what inclusion encompasses. Overall, there is considerable variation in how the group members conveyed inclusion across the data points.

\section{Group B: Kelly and Marcy}

Kelly (Figure 2a) underscored education as a community that everyone deserved to be a part of, where people should love and respect each other and have "access to learning and all opportunities in the world regardless of their similarities and/or differences" (drawing description). A heart brought attention to the affective aspects of inclusion, and she anthropomorphized inclusion itself as an entity emitting "love and acceptance" (drawing description). Kelly's description of everyone deserving to be part of a community accompanies a drawing of a closed circle, paradoxically signaling a closed community and a separation between inclusive and exclusive spaces. Marcy (Figure 2b) addressed inclusion in a geographic sense with "different types of people all together ... in the same space" (drawing description), and in an intangible sense with "the heart being a symbol of love, compassion, and understanding of one another" (drawing description).

Figure 2. Group B Drawings of inclusion.

\section{a. Kelly}

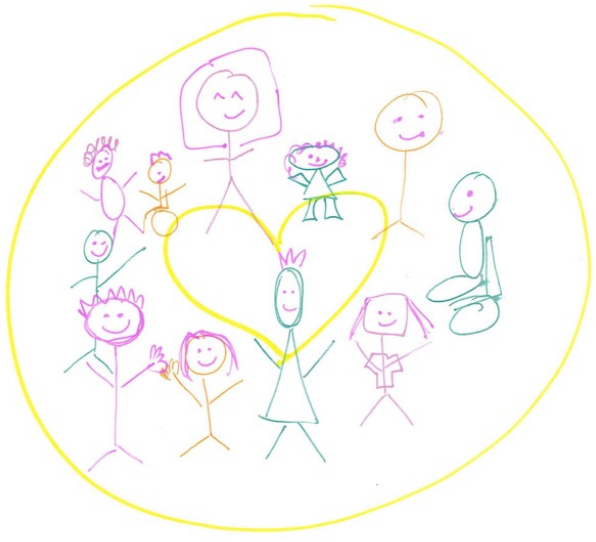

b. Marcy

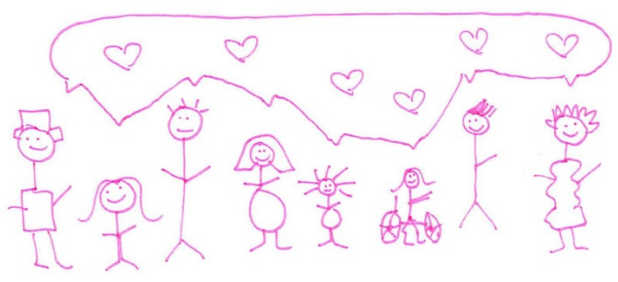

Kelly and Marcy: IEP. Contrasting with Kelly and Marcy's drawings and descriptions, their IEP parent summary made almost no mention of fostering an atmosphere of love or compassion or of the student's positive attributes. Instead they focused on the student's areas of need and goals of "managing aggressive outbursts," "editing [i.e. writing] skills," and "remaining on task" (IEP parent summary). While these goals match the student profile, the student as a person is lost and described primarily in terms of weaknesses and efforts to manage behaviour. Side by side, their drawings and IEP summary convey worlds that seem at odds with each other. 
Kelly and Marcy: UDL. In the UDL assignment, Marcy and Kelly deviated from their initial perspectives of fostering a community, acceptance, and "understanding of one another" (Figure $2 \mathrm{~b}$ drawing description). Instead, they described UDL strategies to support "social skill" development, "positive reinforcement," and "reward[ing] hard work" (UDL assignment). They also mentioned "minimum standards for the students," and efforts to "retain engagement" in service of "remaining on task" (UDL assignment), suggesting a priority of performance.

Kelly and Marcy: Reflection. Kelly's reflection reiterated a belief in fostering "love and happiness" (reflection). She wrote about adding tools and accommodations to support diverse needs while also acknowledging students "have different background knowledge and lives which influence who they are and how they learn" (reflection). Marcy also kept her initial perspectives and described inclusion as "not just about physical differences; it is about our intellectual differences, how we learn, and our learning preferences" (reflection). Their reflections paint a promising picture of inclusion, but there is some disparity in how Kelly and Marcy conveyed an inclusive world across the data points.

\section{Group C: Beth and Emily}

Beth (Figure 3a) used pathways to show that "no matter our abilities we are all on some path of learning" (drawing description), implying inclusion did not require everyone to follow similar or converging paths, such as a specific grade level. She described inclusion as a mechanism for "get[ting] rid of the labels we often associate with people and groups and compel[ling] us to focus on the task at hand, which is to teach to everyone" (drawing description), suggesting teachers spent too much time or effort on labels rather than teaching. Uniquely, Beth integrated an explicit ethical stance, where the teacher not only facilitated inclusion but was also responsible for enabling a "right to learn." Despite positioning the teacher in such a prominent role, Beth did not actually include a teacher in her drawing.

Figure 3. Group C Drawings of inclusion.

a. Beth

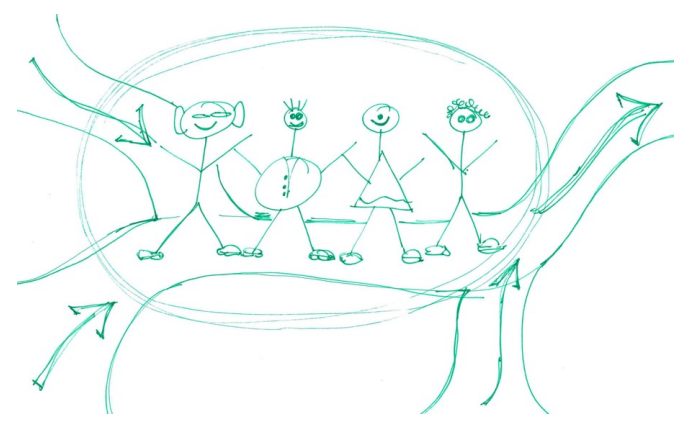

b. Emily

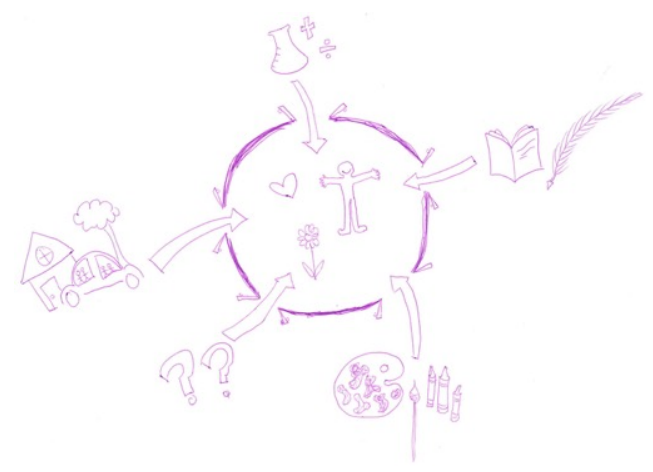


Emily (Figure 3b) described inclusion as a "variety of backgrounds, interests, and subject areas moving into a space" with equitable opportunities for students to participate and "remain comfortable within a space" (drawing description). Her depiction espouses inclusion as a mosaic of diversity and as a segregation between an inner space that engendered "compassion, empathy, welcoming, and support" (drawing description) and an outer space without these qualities. In comparing their drawings, Beth frames inclusion as a journey, whereas Emily portrays inclusion as a common destination. As well, Emily's nod to equal opportunities for involvement and Beth's reference to different learning paths suggest inclusion, for them, did not mean all students had to have the same learning experiences or achievements.

Beth and Emily: IEP. Beth and Emily's IEP parent summary reflected a balance between addressing a student's needs and being optimistic about a student's potential. In addition to listing the student's needs, strengths, and enjoyment of extra-curricular activities, they were confident the student was "capable of learning" and "look[ed] forward to watching [him] grow" (IEP parent summary). Their positive sentiment in the IEP summary partially aligned with their drawings; but notions of empathy, compassion, and a right to learn were less apparent in the IEP.

Beth and Emily: UDL. Like others, Beth and Emily invoked UDL pragmatically. They described a poetry lesson meant to allow students "to explore their individual personalities and interests and present those in their own way" (UDL assignment). Beth and Emily wished to create an enticing environment in which students want to learn. They also discussed how various strategies could benefit all students rather than matching supports to needs at an individual level. Leveraging UDL to offer students choice in how they learn mimics the idea of multiple learning pathways that Beth and Emily initially drew and described.

Beth and Emily: Reflection. Beth expanded her pathways metaphor from people being at the intersection of multiple pathways to people being on unique pathways, acknowledging "not everyone will be ... on the same path" (reflection). She also remarked, "My ideas for ways of teaching are now backed up based on the research I've read in this course as opposed to my own thoughts based on previous experience" (reflection). This comment exemplifies a shift in the resources used to figure a world and a process of integrating new information to bolster existing understanding.

By the course's end, Emily had realized her drawing focused on the outcomes of inclusion but later felt "inclusivity [w]as more of a process" supported by "documentation and ... external resources" (reflection). Her perspective on inclusion had "largely remained the same" (reflection), but she better understood the resources and structures that helped enact inclusion. In general, Beth and Emily communicated common threads about inclusion across each of the course's tasks, with variations in the details as their ideas evolved.

\section{Group D: Judy and Tanis}

Judy described a world that not only welcomed diversity but valued its contribution

to a class (Figure 4a). Holding hands represented mutual respect and the students seeing 
value in what each "student brings to the class and the world around them" (drawing description) An emphasis on students valuing other students' contributions sets Judy's drawing apart from others focused on a general sense of togetherness. In this world, learning and inclusion are distributed responsibilities among students rather than a topdown approach from a teacher. Judy advocated for co-operation and collaboration but tempered these ideals by acknowledging that "students learn from their mistakes" (drawing description) which was also part of inclusion.

Figure 4. Group D Drawings of inclusion.

\section{a. Judy}

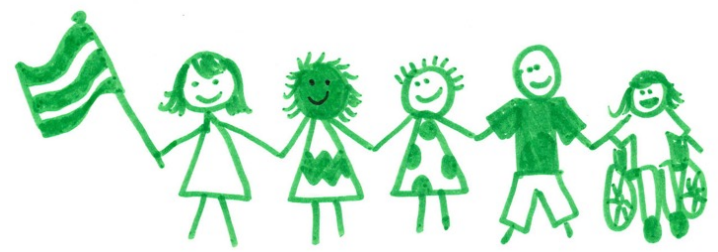

b. Tanis*

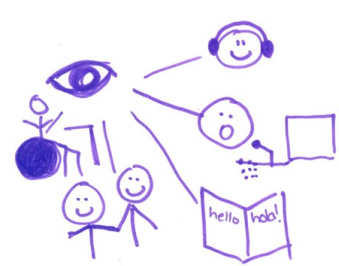

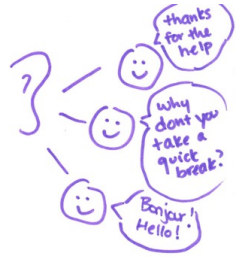

*Note: Speech bubble text, top to bottom, "thanks for the help," "why don't you take a quick break?" "Bonjour! Hello!"

Tanis grappled with how to represent inclusion beyond the few accommodations she knew (Figure 4b). Tanis's humble concession that "inclusion is incredibly hard to draw" (drawing description) points to an understanding of inclusion more complex than she could depict. Her drawing incorporated "the celebration and inclusion of various languages and cultures, ... accommodations," and "assistance ... from teachers, peers, or specialists" (drawing description). In addition, Tanis mentioned inclusion was about the "many ways to help individual learners find success" (drawing description). Tanis appears to appreciate that students experience education in many more ways than a single label or attribute might suggest.

Judy and Tanis: IEP. Judy and Tanis's IEP summary beamed with a positive tone, remarking how the student's "kindness and honesty have made her a great addition to our school environment and [we are] very excited to have the opportunity to help her develop her skills this year" (IEP parent summary). They repeatedly referenced notions of growth, flourishing, development, strengthening, and improvement. Whereas other participants were more neutral or pragmatic in their IEP summaries, Tanis and Judy reinforced the positive and enthusiastic sentiment of their drawings and descriptions.

Judy and Tanis: UDL. In the UDL assignment, Judy and Tanis explained that an open-ended storytelling activity aligned with UDL by being "personally relevant and authentic" (UDL assignment). They wanted students to connect the task with their personal experiences, local community, and "lives inside and outside of school" (UDL assignment), which echoed Judy's initial ideas about seeing "the value that every student brings to the class and the world around them" (drawing description, Figure 4a). 
Judy and Tanis: Reflection. Tanis observed that her perspective had shifted from supporting individual students with disabilities "to supporting all learners" (reflection). She especially resonated with UDL and with "promoting growth mindset in my classroom" (reflection). Judy reiterated learning about, and from, people's differences "rather than ignoring them or being "colour blind"" (reflection), and noted her perspective was unchanged. Throughout the drawings and assignments Judy and Tanis characterized a consistent world.

Tanis: Interview. In her interview, Tanis said her first practicum inspired her initial focus on accommodations (Figure 4b), such as students listening to music to help with focus and using speech-to-text software and dual language books. In her second practicum, Tanis tried to implement UDL but faced "a lot of push back" (interview transcript) from other teachers in the school. She felt other teachers were "hyper-focused" on preparing students to write diploma exams, even though students in her Grade 10 English class would not write diploma exams for another 2 years. Tanis pushed through the resistance and incorporated UDL where possible. For instance, to encourage student engagement during a character analysis for a novel, she incorporated Instagram as a modern tool familiar to students. Even so, Tanis encountered a clash between her world of inclusive ideals and strategies, and the broader world of high school and pressures of academic performance. Tanis juggled these competing demands by trying to reshape the more malleable aspects of the performance driven world she was thrust into. From Tanis's drawing to the interview, she held a positive sentiment of celebrating diversity and helping students grow.

\section{Group E: Melanie and Julia}

Melanie's drawing and description of people holding hands in a circle around a globe exemplifies how participation in one world colours another (Figure 5a). Melanie explained her drawing was meant "to represent globalization, and how races are no longer separated geographically" (drawing description). She cited a focus on "racial inclusion due to my own background, as well as the backgrounds of people in my family" (drawing description), indicating the power of these experiences to fundamentally tint her perspectives toward other worlds.

Connections between students and emotion mattered to Julia (Figure 5b). Her drawing showed multiple "situations that I felt enveloped inclusiveness" (drawing description). She wrote,

Inclusive[ness] to me means welcoming diversity, celebrating and being curious about people's backgrounds, working together, and not leaving people out. Inclusiveness looks like togetherness, a team, looks whole and not fragmented. Inclusiveness feels curious, welcoming, excited, happy, considerate and respectful. Inclusiveness sounds collaborative, it sounds like questions, enthusiasm, and bright, where bright relates to brightening ideas, brightening smiles and brightening spirits.... Inclusiveness is bringing all individuals together, with their ideas and everything they have to offer to create a harmonious unit. (drawing description)

Julia characterizes a world in which people learn from each other, have agency, and share an ethos of valuing diversity. 
Figure 5. Group E Drawings of inclusion.

a. Melanie

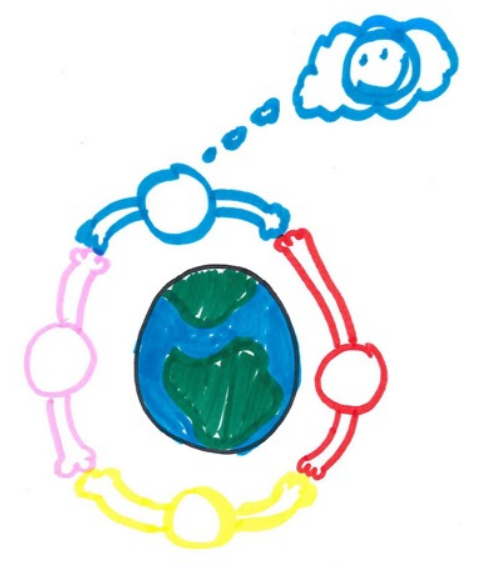

b. Julia*

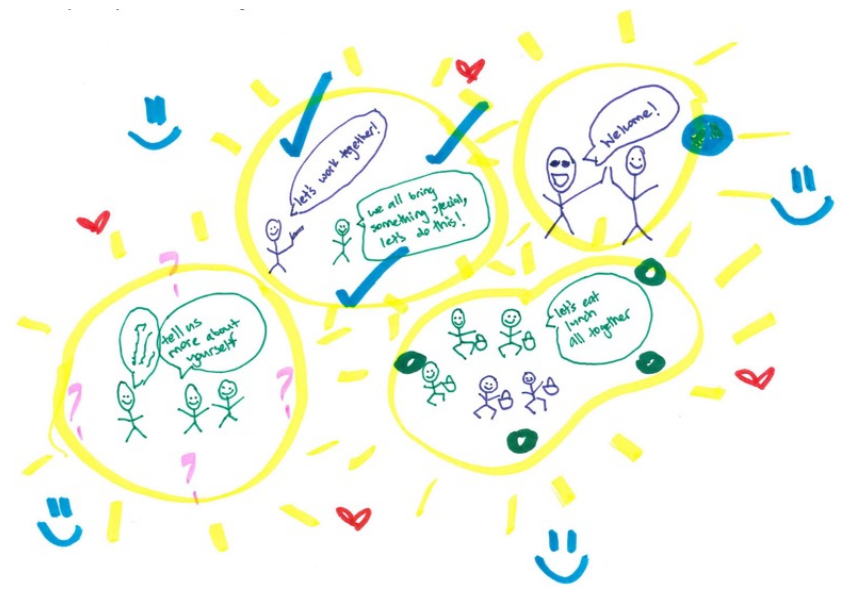

*Note: Speech bubble text, left to right, "tell us more about yourself," "let's work together!" "we all bring something special, lets do this!" "let's eat lunch all together," "Welcome!"

Melanie and Julia: IEP. Melanie and Julia's IEP summary described strategies for collaborative learning, confidence in the student to achieve their goals, and a "collaborative effort from his parents, teachers, other school staff, and [the student]" (IEP summary) to support the student. Their goal of increasing the student's independence and of using a collaborative approach to support them signals a world in which power and responsibility are decentralized. These approaches align with Julia's drawing description, although affective aspects of inclusion such as being curious, happy, or excited were less apparent in the IEP summary.

Melanie and Julia: UDL. In the UDL assignment, Melanie and Julia used sexuality, gender identity, and social justice as a lesson topic to challenge "students' preconceived notions and assumptions about sex, gender, and sexual orientation, while encouraging them to have an open heart and mind" (UDL assignment). They described whole-class efforts to encourage "friendships and help students feel involved," belonging, and relevance "to their life outside of the classroom" (UDL assignment), which like the IEP, matched the thoughtful language in their drawing descriptions.

Melanie and Julia: Reflection. Julia's reflection expanded her initial ideas to include considerations for "behaviour, emotion, and cognition" (reflection) in concert with UDL and IEPs. She wrote, "inclusion is not only a way of acting, but also a way of thinking to demonstrate universal acceptance and to promote a sense of belonging" (reflection). Melanie also advanced her thinking by refocusing from broad globalization and general acceptance to "how we'll be inclusive in our classrooms" by employing "UDL principles, ... assistive technology, and multiple ways to keep students engaged" (reflection). 
Julia: Interview. In her interview Julia explained that her childhood experiences learning English as a third language inspired her drawing. She spoke fondly of peers being accepting and understanding of her learning English. It was a world she lived and wished to recreate. During her practicum, she strived to find students' strengths while maintaining "really high expectations" (interview transcript). Julia sometimes felt students with disabilities "weren't getting pushed at home" (interview transcript) to reach the potential she believed they were capable of, as though parents' or guardians' expectations were lowered because of the students' disabilities. Julia also faced tension when some students struggled with learning but were undiagnosed with a disability, or when their parents downplayed a student's struggles, which meant those students had no or limited access to accommodations. Nevertheless, Julia described using free online tools and available resources to offer multiple ways for students to express their learning. She reiterated relationships as key to developing trust and supporting students' needs. Overall, Julia's tone and recounting of experiences during her practicum aligned closely with the enthusiasm expressed in her drawing and description, and her group tasks with Melanie were consistent in conveying inclusion.

\section{Discussion}

\section{Inclusion as a Utopian World}

All participants broadly presented inclusion as a beneficial and desirable practice, echoing the positive sentiments found in earlier research (Sokal \& Sharma, 2017). Upon closer inspection, the nuances and focuses of how the participants represented inclusion - the characters, acts, outcomes, and values that made up a world (Holland et al., 1998) — varied across the data. In the drawings and descriptions, a teacher was key to all the participants in fostering inclusion, although only Alice actually drew a teacher. In such worlds, a teacher is an invisible character of inclusion. Placing responsibility on the teacher also maps to a social perspective toward inclusion, where a teacher and school adapt to student needs rather than vice versa (Jordan \& Stanovich, 2003). Within the drawings and descriptions there were also variations in how a teacher approached inclusion. Alice described inclusion in terms of academic performance, while Kelly wrote of fostering love and happiness, for example. This finding parallels observations by Savolainen et al., (2012), who found that teachers in South Africa framed inclusion around behaviour management while Finnish teachers emphasized collaboration and interpersonal relationships among students. In both cases, the participants valued inclusion but expressed markedly different approaches.

The participants' drawings and descriptions conveyed inclusion as a utopian world. In these utopian spaces, students were frequently depicted as smiling or expressing positive emotions, and the participants often referenced notions of love, acceptance, or compassion. The near ubiquitous, yet unspecified, relationship between smiling and inclusivity in the participants' drawings echoes related studies of how teachers are portrayed in drawings and visual media (Joseph \& Burnaford, 1994; Weber \& Mitchell, 1995). In those studies, teachers and students were nearly always shown as smiling, which was argued to signal affection and care. While not problematic in themselves, smiles only reflect some of the emotions and experiences that can occur within an 
inclusive environment. As McWilliams (2016) cautioned, narratives of progress or increased participation should not be the sole markers of successful learning. Navigating tension and conflict is equally part of learning and are precursors to inclusion.

The participants also expressed multiple types of diversity and consistently valued fostering relationships between diverse people. Although the drawing task was ungraded and there were no requirements beyond responding to the drawing prompt, the tendency to explicitly showing a breadth of diversity suggests an unspoken sense of pressure on the participants. In figuring a world, perceptions of social capital come into play as people attribute value and significance to elements of a world (Holland et al., 1998). The participants had to share their drawings with peers and the instructors, so it seems showing more forms of diversity was a way to be perceived as more inclusive. At the same time, the participants often referenced such broad categories of diversity (e.g., abilities, backgrounds), that discerning how inclusion might look in practice was sometimes difficult.

The participants often depicted students collaborating and being part of a community that coalesced diverse backgrounds, interests, and experiences. These ideals align with the broader, social models of teaching and learning promoted in contemporary (Western) educational theory (Illeris, 2018). Perhaps because the participants were not asked to describe in detail how they might create their ideal environments, the complexities of a real-world classroom were largely unspecified. For example, the term "community" is general and imprecise, making it unclear what the participants really meant aside from presuming communities are inherently good (Philip et al., 2013). At the time of the drawing activity, the participants had positive sentiments toward inclusion but had yet to flesh out the details of how inclusion might look in practice or the many facets that make inclusion.

\section{Enacting Inclusion in a Pragmatic World}

While the drawings represent the participants' ideals for inclusion, the IEP and UDL assignments, the reflection, and the practicum placements were a chance for the participants to revisit their ideas and apply them to each context (e.g., individual support, personal reflection, whole class support, real-world).

Many of the participants' utopian ideals were absent in the IEP parent summary. An IEP takes an inherently deficit-oriented approach to inclusion by pinpointing areas of need, developing goals, and organizing supports to guide a student closer to standardized expectations of academic performance (Andrews \& Lupart, 2015). Unsurprisingly, the participants' utopian ideals sometimes contradict the highly structured and psychometric underpinnings of an IEP (Andrews \& Lupart, 2015). The participants often oscillated between performance-based and holistic-oriented language. For example, in their IEP summary, Kelly and Marcy described managing student behaviour, remaining on task, and monitoring progress, which align with behaviourist approaches (Davis et al., 2015). Simultaneously, they hoped the student would become a lifelong learner, which aligns with more growth-oriented approaches (Hart et al., 2004).

Similarly, notions of community and collaboration were mentioned in the IEP and UDL assignments, but often to address behavioural concerns for a student. A focus on 
behaviour management conjures a world that privileges specific types of behaviour deemed socially acceptable. Understandably, extreme behaviours (e.g., physical or emotional harm) can be concerning, but students should also not be constrained to narrow ways of learning. For example, teachers can be quick to correct students' use of "incorrect" language or terms and inadvertently discourage students' participation for fear of being "wrong" (e.g., students using "hotness" to describe temperature; Rosebery et al., 2010). Conversely, embracing heterogeneous ways of learning can spark generative discourse, agency, engagement, and inclusion among students (Rosebery et al., 2010). Such approaches redirect from a focus on behaviour management to valuing students' contributions because of, not despite, their diversity. Some participants wrote in their drawing descriptions about valuing students' contributions but did not carry forward or explain how these ideas could be implemented in the other assignments.

In the UDL assignment, three participant groups trended closer to the ideas they expressed in their drawings and descriptions. This seems appropriate given that UDL, in part, is a road map for fostering inclusive learning, which overlaps more readily with the participants' ideals (Forlin \& Loreman, 2014; Meyer et al., 2014). There are parallels between the pathways in Beth's and Emily's drawings and descriptions, and their strategy for offering agency and choices to students in the UDL assignment. Similarly, Judy and Tanis acknowledged students' experiences outside of school in their drawings and descriptions, while also wanting to make in-school learning relevant beyond the classroom in their UDL assignment. Likewise, Julia and Melanie addressed students' diverse backgrounds coming together in their drawings and descriptions, and they reiterated this sentiment in the UDL assignment by encouraging students to learn about different sexualities and gender identities.

The discussions of UDL by all the participants skewed toward pragmatic matters of accessibility and accommodating student needs, but the three groups noted above balanced the pragmatics by encouraging agency and going deeper in making learning personally relevant to students. Figuring inclusion in this more comprehensive way addresses a common misconception of UDL as merely the use of multimedia or a list of students' needs matched to accommodations (Edyburn, 2010), such as how Cheryl, Alice, and Susan approached the UDL assignment. Kelly and Marcy seemed to also interpret UDL primarily as a toolkit for supporting academic performance and efficiency in their assignment. Absent from their UDL assignment were the references to love, community, and compassion expressed in their drawings and descriptions. Each data point reflected an instance of the participants re-figuring an inclusive world, yet it seems that for some participants, each instance of figuring was separate. Many of the participants' utopian ideals (e.g., emotion, relationships, pathways) align with the UDL principles, but the participants did not appear to recognize or make such connections.

Most participants presented two adjacent figured worlds of inclusion, one for the ideals of inclusion and one for pragmatic strategies. These worlds were connected and related but not integrated as one. The participants held promising ideals of inclusion, but they either had yet to develop a self-awareness and intention for how to consistently apply their ideals in different scenarios (e.g., individual versus class-wide supports) or they encountered context-specific barriers. Julia was an exception in having strong consistency throughout course tasks and practicum, and she had worked to overcome barriers. As she 
explained in her interview, she could not only describe a world of inclusion, but she also lived it. Holland et al. (1998) described this as the long-term development of a positional disposition that guides actions rather than cursory-level participation of what could or should be; in other words, reaching a level of inclusion as part of instinctual everyday actions versus as part of selective circumstances. Julia's experiences as an English language learner anchored her ideas and gave meaning to how she approached inclusion. Esmonde (2014) similarly described this as the difference between learning about a world versus learning within a world. As another example, Cheryl's daughter's recent learning disability diagnosis had thrust Cheryl into the world of disability education and reshaped her understanding of inclusion from within that world.

Figuring is a process dependent on the discourses and experiences available to a person to construct a figured world (Holland et al., 1998; Naraian, 2010). For instance, Alice noted heavy influence from her experiences as a piano teacher and was more performance oriented in her drawing and description. Similarly, Melanie's reference to racial inclusion in her drawing and description was motivated by her personal experiences. Figuring a world invokes past experiences as well as present resources and discourses, which can at times be at odds. In her interview, Tanis described facing tensions between how she figured inclusion and the school culture of her practicum placement, which changed what resources and discourses were available to her. She had to reconcile her ideals with the existing structures and norms of her practicum school. Figuring an inclusive world was now much more complex than Tanis, and likewise Julia, had initially conveyed - trying to weave inclusive practices within traditional structures of schooling can be a challenge (Naraian, 2010). At the same time, figured worlds are dynamic and socially negotiated, so Tanis's and Julia's persistence in incorporating inclusive practices contribute to an ongoing, broader discourse of figuring inclusion.

\section{Implications}

The findings show how the participants navigated the process of figuring inclusion across different situations. For most participants, there were marked differences in how inclusion was conveyed in the drawings and descriptions versus the other data sources. Beyond Julia, however, the given data set is unclear about why participants were more or less consistent in how they described inclusion, suggesting an area for future study. The participants seemed caught between progressive ideals of inclusion, the pragmatic strategies of inclusion, and the historical legacy of using psychometrics to categorize students. These tensions are perhaps equally a metaphor of inclusion within the broader education system, in which there are competing demands between resources, inclusive ideals, and performative expectations (Andrews \& Lupart, 2015). Supporting pre-service teachers to recognize and respond to such tensions seems crucial for teacher education to take up. As well, future research could explore how pre-service teachers reconcile conflicting perspectives and how these tensions shape teaching practices and classroom students' experiences. As pre-service teachers begin their teaching careers, an awareness of and reflexivity toward their practices and those around them will be key in best supporting students rather than just maintaining the status quo (Thorius, 2016). 
The drawing activity offered an alternative way for pre-service teachers to convey their ideas as well as an alternative data source for interpretation. One modification to the design could be to give pre-service teachers more time to complete their drawings and revise them as their ideas evolve. This could give pre-service teachers opportunities to formulate a more comprehensive representation of inclusion (e.g., Phillipson \& Forlin, 2011) and could be paired with other activities to help pre-service teachers reflect on how they think about inclusion in different scenarios and frames of reference (e.g., individual versus whole-class or school). Encouraging pre-service teachers to critically reflect on their perspectives as they encounter different forces (e.g., policy, school culture, parents) can help them become more robust in navigating such forces. In subsequent iterations of this course, having pre-service teachers collaborate on drawings or artistic representations of inclusion has shown promise as a way for pre-service teachers to engage their peers' perspectives and negotiate an understanding of inclusion. Employing a drawing activity after pre-service teachers have had multiple practicums, or employing it with in-service teachers, could similarly support teachers as they critically reflect on how inclusion is figured in their own contexts, to identify opportunities to re-figure practices to better support students' needs.

\section{Conclusion}

The findings indicate a much messier interpretation of inclusion by pre-service teachers than would be suggested by the linear way in which inclusion is often taught. Pre-service teachers have promising ideals but do not necessarily know how to, nor are able to, connect them when considering different circumstances and scopes of support. Further, teacher educators cannot assume pre-service teachers come with equally sophisticated understandings of inclusion. Navigating the competing demands of ideals, pragmatics, and systemic structures is no easy feat, and even within the simplified context of a course, the findings bring to light the complexities pre-service teachers must contend with. The findings suggest pre-service teachers would benefit from scaffolding to connect their ideals with theory and practice, and to become more self-aware of whether their practices consistently align with their ideals. These alignments matter given that teacher education programs can affect how pre-service teachers think about teaching and learning for years to come.

\section{References}

Albers, P. (2007). Visual discourse analysis: An introduction to the analysis of school-generated visual texts. In D. W. Rowe, R. T. Jimenez, D. L. Compton, D. K. Dickinson, Y. Kim, K. M. Leander, \& V. J. Risko (Eds.), 57th yearbook of the National Reading Conference (pp. 8195). National Reading Conference.

Albers, P., Frederick, T., \& Cowan, K. (2009). Features of gender: An analysis of the visual texts of third grade children. Journal of Early Childhood Literacy, 9(2), 234-260. https://doi.org/10.1177/1468798409105588

Alberta Teachers' Association. (2015). The state of inclusion in Alberta schools. http://www.deslibris.ca/ID/247446

Andrews, J., \& Lupart, J. L. (Eds.). (2015). Diversity education: Understanding and addressing student diversity. Nelson Education. 
Bennett, D., Solomon, Y., Bergin, C., Horgan, M., \& Dornan, T. (2017). Possibility and agency in figured worlds: Becoming a 'good doctor.' Medical Education, 51(3), 248-257. https://doi.org/10.1111/medu.13220

Burke, K., \& Sutherland, C. (2004). Attitudes toward inclusion: Knowledge vs. experience. Education, 125(2), 163-172.

Davis, B., Sumara, D. J., \& Luce-Kapler, R. (2015). Engaging minds: Cultures of education and practices of teaching (3rd ed.). Routledge.

DePoy, E., \& Gilson, S. F. (2011). Studying disability: Multiple theories and responses. SAGE.

Edyburn, D. L. (2010). Would you recognize Universal Design for Learning if you saw it? Ten propositions for new directions for the second decade of UDL. Learning Disability Quarterly, $33(1), 33-33$.

Esmonde, I. (2014). "Nobody's rich and nobody's poor ... it sounds good, but it's actually not": Affluent students learning mathematics and social justice. Journal of the Learning Sciences, 23(3), 348-391. https://doi.org/10.1080/10508406.2013.847371

Forlin, C., \& Loreman, T. (Eds.). (2014). Measuring inclusive education. Emerald.

Gee, J. P. (2011). An introduction to discourse analysis: Theory and method (3rd ed.). Routledge.

Hart, S., Dixon, A., Drummond, M. J., \& McIntyre, D. (2004). Learning without limits. Open University Press.

Holland, D., Lachicotte, W., Skinner, D., \& Cain, C. (1998). Identity and agency in cultural worlds. Harvard University Press.

Illeris, K. (Ed.). (2018). Contemporary theories of learning: Learning theorists in their own words (2nd ed.). Routledge.

Jordan, A., \& Stanovich, P. (2003). Teachers' personal epistemological beliefs about students with disabilities as indicators of effective teaching practices. Journal of Research in Special Educational Needs, 3(1). https://doi.org/10.1111/j.1471-3802.2003.00184.x

Joseph, P. B., \& Burnaford, G. E. (Eds.). (1994). Images of schoolteachers in twentieth-century America: Paragons, polarities, complexities. St. Martin's Press.

Kim, J. (2011). Influence of teacher preparation programmes on preservice teachers' attitudes toward inclusion. International Journal of Inclusive Education, 15(3), 355-377. https://doi.org $/ 10.1080 / 13603110903030097$

Kress, G., \& van Leeuwen, T. 2006. Reading images: The grammar of visual design (2nd ed.). Routledge.

Lawrence-Brown, D., \& Sapon-Shevin, M. (Eds.). (2014). Condition critical: Key principles for equitable and inclusive education. Teachers College Press.

Loreman, T., \& Earle, C. (2007). The development of attitudes, sentiments and concerns about inclusive education in a content-infused Canadian teacher preparation program. Exceptionality Education International, 17(1), 85-106.

Markova, M., Pit-Ten Cate, I., Krolak-Schwerdt, S., \& Glock, S. (2016). Preservice teachers' attitudes toward inclusion and toward students with special educational needs from different ethnic backgrounds. The Journal of Experimental Education, 84(3), 554-578. https://doi.org /10.1080/00220973.2015.1055317

McKenney, S. E., \& Reeves, T. C. (2012). Conducting educational design research. Routledge.

McWilliams, J. (2016). Queering participatory design research. Cognition and Instruction, 34(3), 259274. https://doi.org/10.1080/07370008.2016.1172436 
Meyer, A., Rose, D. H., \& Gordon, D. (2014). Universal Design for Learning: Theory and practice. CAST.

Morris, S., Fawcett, G., Brisebois, L., \& Hughes, J. (2018). A demographic, employment and income profile of Canadians with disabilities aged 15 years and over, 2017 (Cat. no.: 89-654-X2018002). Statistics Canada. https://www150.statcan.gc.ca/n1/pub/89-654-x/89-654-x2018002-eng.htm

Naraian, S. (2010). General, special and ... inclusive: Refiguring professional identities in a collaboratively taught classroom. Teaching and Teacher Education, 26(8), 1677-1686. https://doi.org/10.1016/j.tate.2010.06.020

National Centre for Education Statistics. (2019). Children and youth with disabilities. Retrieved from https://nces.ed.gov/programs/coe/indicator_cgg.asp

Philip, T. M., Way, W., Garcia, A. D., Schuler-Brown, S., \& Navarro, O. (2013). When educators attempt to make "community" a part of classroom learning: The dangers of (mis)appropriating students' communities into schools. Teaching and Teacher Education, 34, 174-183. https://doi.org/10.1016/j.tate.2013.04.011

Phillipson, S., \& Forlin, C. (2011). Newly qualifying teachers' perspectives of diversity and inclusion: Understanding through visual representations. International Journal of Whole Schooling, $7(1), 1-19$.

Robinson, C. (2007). Figured world of history learning in a social studies methods classroom. The Urban Review, 39(2), 191-216. https://doi.org/10.1007/s11256-007-0046-x

Rosebery, A. S., Ogonowski, M., DiSchino, M., \& Warren, B. (2010). "The coat traps all your body heat": Heterogeneity as fundamental to learning. Journal of the Learning Sciences, 19(3), 322-357. https://doi.org/10.1080/10508406.2010.491752

Savolainen, H., Engelbrecht, P., Nel, M., \& Malinen, O.-P. (2012). Understanding teachers' attitudes and self-efficacy in inclusive education: Implications for pre-service and in-service teacher education. European Journal of Special Needs Education, 27(1), 51-68. https://doi.org $/ 10.1080 / 08856257.2011 .613603$

Silverman, J. C. (2007). Epistemological beliefs and attitudes toward inclusion in pre-service teachers. Teacher Education and Special Education, 30(1), 42-51. https://doi.org $/ 10.1177 / 088840640703000105$

Sokal, L., \& Sharma, U. (2017). "Do I really need a course to learn to teach students with disabilities? I've been doing it for years." Canadian Journal of Education, 40(4), 739-760.

Thorius, K. A. K. (2016). Stimulating tensions in special education teachers' figured world: An approach toward inclusive education. International Journal of Inclusive Education, 20(12), 1326-1343. https://doi.org/10.1080/13603116.2016.1168877

Weber, S., \& Mitchell, C. (1995). That's funny, you don't look like a teacher! Interrogating images and identity in popular culture. Falmer Press.

\section{Author's Note}

Correspondence concerning this article should be addressed to Christopher Ostrowdun, 2500 University Drive NW, Calgary, AB, T2N 1N4, Canada. Email: chris.ostrowdun@ucalgary.ca 